\title{
The effect of soil and cable backfill thermal conductivity on the temperature distribution in underground cable system
}

\author{
Monika Rerak $^{1}$, and Pawel Ocłoń ${ }^{1, *}$ \\ ${ }^{1}$ Cracow University of Technology, Institute of Thermal Power Engineering, al. Jana Pawła II 37, 31-864 Krakow, Poland
}

\begin{abstract}
The paper presents a mathematical model of heat transfer in the underground cable system. The computations were performed for flat formation of power cables buried in the ground at a depth of 2 meters. The model allows determining the two-dimensional temperature distribution in the soil, thermal backfill and power cables. The simulations studied the effect of soil thermal conductivity on the maximum temperature of the cable conductor. Furthermore, the effect of thermal backfill soil conductivity on the cable conductor temperature was studied. Numerical analyses were performed based on a program written in MATLAB.
\end{abstract}

\author{
Nomenclature \\ Roman Symbols \\ A cross-sectional area, $\mathrm{m}^{2}$ \\ the distance between the conductors' \\ $b \quad$ axes and the bottom of cable bedding \\ layer, $\mathrm{m}$ \\ $C \quad$ length of the sample, $\mathrm{m}$ \\ $f \quad$ frequency, $\mathrm{Hz}$ \\ $H \quad$ computational domain height, $\mathrm{m}$ \\ $h \quad$ burial depth, $m$ \\ I current loading, A \\ $k \quad$ thermal conductivity, $\mathrm{W} /(\mathrm{m} \mathrm{K})$ \\ $k_{s}, k_{p} \quad$ skin and proximity effect correction \\ factors, - \\ the spacing between two consecutive \\ cables, $\mathrm{m}$ \\ the distance between the conductors' \\ $p \quad$ axes and the top of cable bedding layer, \\ $\mathrm{m}$ \\ $q_{v} \quad$ volumetric heat source, $\mathrm{W} / \mathrm{m}^{3}$ \\ $R_{e, A C}$ alternating current (AC) resistance, \\ $\Omega / \mathrm{km}$
}

\section{Introduction}

When designing the underground electricity network, the thermal phenomena shall be considered. Due to the cable insulation meltdown occurrence, the cable conductor temperature shall not exceed $90^{\circ} \mathrm{C}$. Since the data on soil thermal resistance is mostly uncertain, the cable engineers design the underground power system in such a way that the cable core temperature does not exceed

$$
\begin{array}{ll}
R_{e, D C} & \begin{array}{l}
\text { direct current (DC) resistance, } \Omega / \mathrm{km} \\
\text { reference cable conductor electrical }
\end{array} \\
R_{e, r e f} & \begin{array}{l}
\text { resistance (calculated for } 20^{\circ} \mathrm{C} \text { ), } \Omega / \mathrm{km} \\
\text { the spacing between the right edge of the }
\end{array} \\
S & \begin{array}{l}
\text { bedding layer and the side cable axis, } \mathrm{m} \\
\text { temperature, }{ }^{\circ} \mathrm{C}
\end{array} \\
T & \text { computational domain width, } \mathrm{m} \\
W & \text { Cartesian coordinates, }- \\
x, y & \text { skin and proximity coefficients, }-
\end{array}
$$

$\begin{array}{ll}\text { Subscripts } \\ b & \text { backfill, } \\ c & \text { cable conductor, } \\ g & \text { ground, } \\ \text { ins } & \text { cable insulation, } \\ s & \text { soil, }\end{array}$

\section{Greek Symbols}

$\begin{array}{ll}\alpha_{e, r e f} & \begin{array}{l}\text { temperature coefficient, - } \\ \text { specific electrical resistance of the copper } \\ \rho_{20}\end{array} \\ \Delta Q \quad \begin{array}{l}\text { conductor in } 20^{\circ} \mathrm{C}, \Omega \mathrm{m} \\ \text { cable conductor heat losses, } \mathrm{W}\end{array}\end{array}$

the optimum temperature of cable operation $\left(65^{\circ} \mathrm{C}\right)$. Therefore, the cable engineers in many cases use thermal backfill materials for locating the power cables. The cable backfill material exhibits higher thermal conductivity than the mother soil. Therefore, the heat dissipation from the buried cables to surroundings is enhanced, when compared to the cables situated in the native soil.

Thermal analysis of the underground power cables operation was performed in [1-5], among others. Both the

* Corresponding author: poclon@mech.pk.edu.pl 
numerical and experimental investigations were conducted. Hwang and Jiang [1] presented a combined nonlinear magnetothermal analysis, including radiation effects, for calculating the thermal fields of an underground cable system. Al-Saud et al. [2] performed the numerical computations of temperature distribution in soil and underground power cables. A new perturbed finite-element analysis technique was developed. AlSaud's approach involves the use of derived sensitivity coefficients associated with various cable parameters of interest, and use these coefficients to achieve optimal cable performance. De Lieto Vollaro et al. [3] performed a numerical study based on a Control-Volume Formulation of the Finite-Difference Method. That technique was used to determine the thermal resistance existing between an underground electrical power cable and the ground surface. The thermal behavior of the cables system was studied for various dimensions of the trench, cable burial depth, two backfill layers thicknesses, and the cable bedding. The authors developed a semiempirical correlating equation using multiple regression procedures and verified proposed model experimentally in [4]. Kroener et al [5] presented the comprehensive approach to determining the cable ampacity. The authors developed the new numerical model of coupled liquid water, vapor and heat flow in a thermal system that consists of underground cable buried in the soil. The transient computations performed using the Finite Element Method were verified experimentally and demonstrated the strong relation of the cable temperature on soil water content. The thermal analysis of underground power cable systems were also presented in [6-10]. The optimization of thermal backfill dimensions was presented in [6,7], and the computational studies of multilayered soil effect [8] and various cable placement type $[9,10]$ were performed .

This study presents a numerical model of underground power cable system. Three power cables arranged in the flat (in-line) formation and buried at a depth of $2 \mathrm{~m}$ are considered. The influence of soil thermal conductivity and thermal backfill conductivity on the maximum cable core temperature is studied. The numerical code developed in MATLAB software allows calculating the two-dimensional temperature distribution within the underground power cable system including cable core, thermal backfill, and soil. The presented mathematical model is efficient and straightforward in programming implementation.

\section{Mathematical model of underground power cable system}

The scheme of the computational domain is shown in Fig. 1 :

\section{ground level}

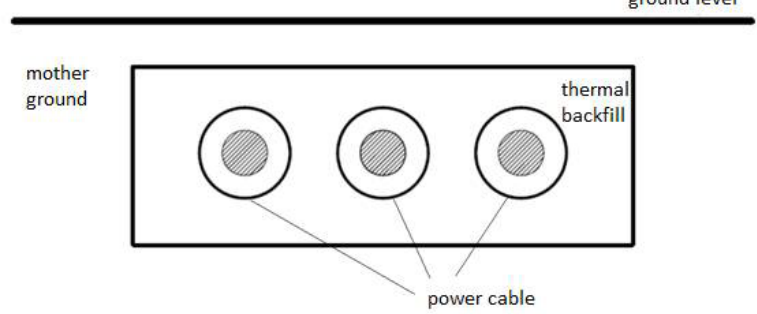

Fig. 1. Flat formation of underground power cable system.

Figure 2 depicts the characteristic dimensions of the system.

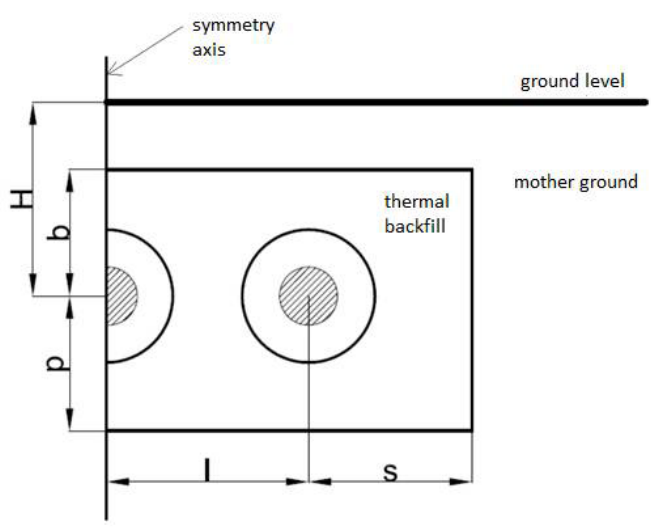

Fig. 2. Characteristic dimensions of the cable system.

The following dimensions are shown in Fig. 2

$l$ - spacing between two consecutive cables (assumed as $0.4 \mathrm{~m}$ in this study),

$s$-distance from the right edge of the backfill layer to the side cable axis (assumed as $0.4 \mathrm{~m}$ in this study),

$b$ - distance from the conductor's axis to the top of bedding layer (assumed as $0.4 \mathrm{~m}$ in this study),

$p$-distance between the conductor's axis and the bottom of bedding layer (assumed as $0.4 \mathrm{~m}$ in this study),

The cable conductor cross section $A_{c}$ is selected from the XLPE HV cable design series provided by the cable producer, and equal to $A_{c}=1400 \mathrm{~mm}^{2}$.

The computational scheme is given in Fig. 3a while the grid used in the analysis is shown in Fig. $3 b$. 
a)

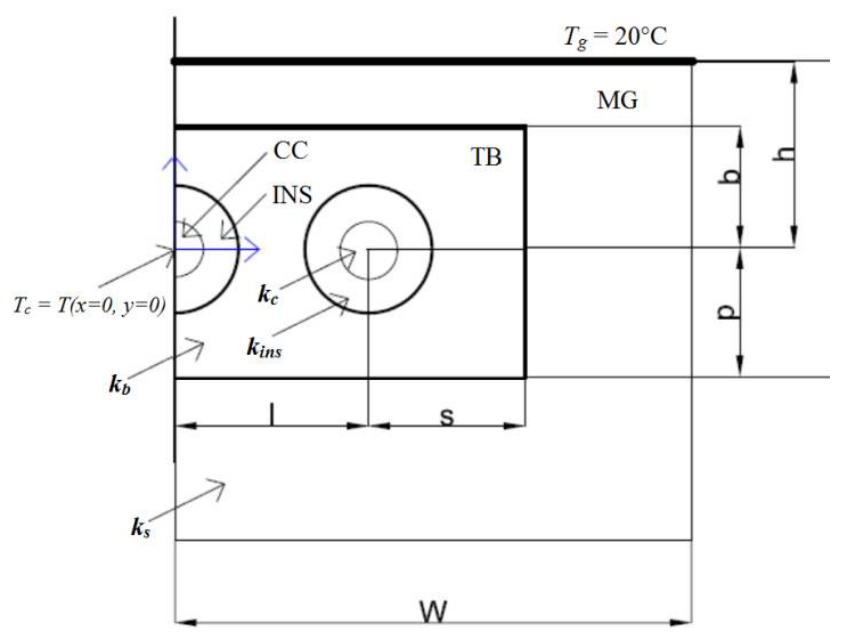

b)

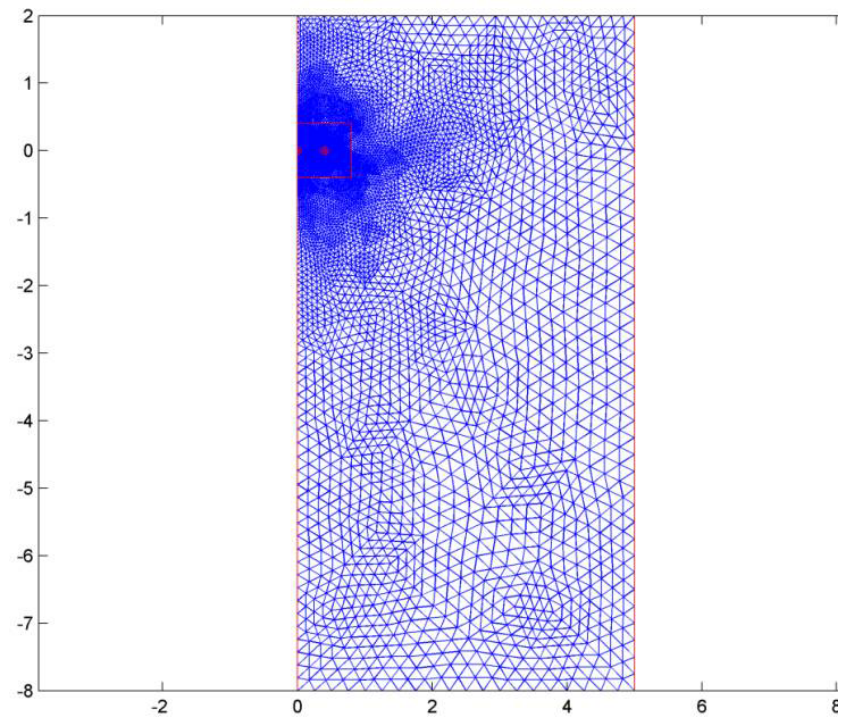

Fig. 3. a) the computational scheme b) computational grid.

The Underground Power Cable System (UPCS) computational domain consists of four subdomains:

- $\quad$ Mother ground (MG),

- Thermal Backfill (TB),

- $\quad$ Cable conductor (CC),

- Cable insulation (INS).

The temperature at certain point with $(x, y)$ coordinates is calculated from the heat conduction equation [8]:

$$
\frac{\partial}{\partial x}\left[k \frac{\partial T(x, y)}{\partial x}\right]+\frac{\partial}{\partial y}\left[k \frac{\partial T(x, y)}{\partial y}\right]=-q_{v}\left(T_{c}(x, y)\right)
$$

where:

$T_{c}$ - cable conductor temperature, ${ }^{\circ} \mathrm{C}$

$q_{v}$ - volumetric heat source (valid only for cable conductor domain), $\mathrm{W} / \mathrm{m}^{3}$.

$k$ - thermal conductivity, $\mathrm{W} /(\mathrm{m} \mathrm{K})$,

The thermal conductivity values for power cable layers are assumed according to Table 1 . The soil thermal conductivity is varied from $0.5 \mathrm{~W} /(\mathrm{m} \mathrm{K})$ to $1 \mathrm{~W} /(\mathrm{m} \mathrm{K})$ and depends on the computational case. The thermal backfill conductivity is ranged from $1 \mathrm{~W} /(\mathrm{m} \mathrm{K})$ to $3 \mathrm{~W} /(\mathrm{m}$ $\mathrm{K})$ ).

Table 1. Cable layer dimensions and thermal conductivities

\begin{tabular}{|c|c|c|}
\hline $\begin{array}{c}\text { Cable } \\
\text { layer }\end{array}$ & Material & $\begin{array}{c}\text { Thermal } \\
\text { conductivity, } \\
\mathbf{W} /(\mathbf{m} \cdot \mathbf{K})\end{array}$ \\
\hline Conductor & Copper & 400.00 \\
\hline Insulation & XLPE & 0.3232 \\
\hline
\end{tabular}

The volumetric heat source is given as:

$$
q_{v}(T(x, y))=\frac{\Delta Q}{A_{c}}
$$

Where the heat losses $\Delta Q$ are calculated based on the current rating $I=1000$ A and the alternating current (AC) electric resistance $R_{e, A C}$ :

$$
\Delta Q=I^{2} R_{e, A C}
$$

The altering current electrical resistance is a function of direct current electrical resistance $R_{e, D C}$ and skin and proximity coefficients denoted as $y_{s}$ and $y_{p}$, respectively:

$$
R_{e, A C}=R_{e, D C}\left(1+y_{s}+y_{p}\right)
$$

with

$$
R_{e, D C}=R_{e, r e f}\left[1+\alpha_{r e f}\left(T(x, y)-T_{r e f}\right]\right.
$$

where, $R_{e, \text { ref }}$ and $\alpha_{e}$,ref are the reference cable conductor's electric resistance, and the temperature coefficient for the conductor material, both given at the reference temperature $T_{r e f}=20^{\circ} \mathrm{C}$. The reference electric resistance of the cable conductor is given by:

$$
R_{e, r e f}=\frac{\rho_{20} C}{A_{c}}
$$

where,

$\rho_{20}$ - specific electrical resistance of copper conductor in $20^{\circ} \mathrm{C}, \Omega \cdot \mathrm{m}$; for the following case study $\rho_{20}=1.724110$ $8 \Omega \cdot \mathrm{m}$,

$C$ - length of the sample, $\mathrm{m} ; C=1.0 \mathrm{~m}$,

$A c$ - cable conductor area, $\mathrm{m}^{2}$,

the temperature coefficient for copper conductor $\alpha_{e}$,ref is equal to 0.00393 .

The skin and proximity effect coefficients $y_{s}$ and $y_{p}$ are determined from the following relationships:

$$
y_{s}=\frac{x_{s}^{2}}{192+0.8 x_{s}^{2}}, x_{s}=\frac{8 \pi f}{R_{e, D C}} \cdot 10^{-7} k_{s}
$$

$$
y_{p}=\frac{x_{p}^{2}}{192+0.8 x_{p}^{2}}\left(\frac{d_{c}}{l}\right)^{2}\left[0.312\left(\frac{d_{c}}{l}\right)^{2}+\frac{1.18}{\frac{x_{p}^{2}}{192+0.8 x_{p}^{2}}+0.27}\right] \text {, }
$$




$$
x_{p}=\frac{8 \pi f}{R_{e, D C}} \cdot 10^{-7} k_{p}
$$

Where, $k_{s}$ and $k_{p}$ are skin and proximity effect correction factors equal to 0.435 and 0.37 , respectively, for the case of segmented conductor type[8]. An alternating current frequency $f=50 \mathrm{~Hz}$ and $l$ is the distance between adjacent conductor axes.

\subsection{Boundary condition}

The symmetry pattern of the heat conduction equation solution is expected. Therefore only the half of the computational domain is considered. Hence,

the square domain with a height of $10.0 \mathrm{~m}$ and width of $5.0 \mathrm{~m}$ is used in the computations (Fig. 3). It is assumed that the right, left and bottom edges of the boundary region are perfectly insulated. At the top edge (the ground level), the temperature $T_{g}$ is set to $20^{\circ} \mathrm{C}$. This temperature value is specified by the standards [11,12]. The mathematical description of the applied boundary conditions is given by Eq. (9).

$\left.k \frac{\partial T}{\partial x}\right|_{x=W}=0$, for the boundary region right edge,

$\left.k \frac{\partial T}{\partial x}\right|_{x=0}=0$, for the symmetry plane,

$\left.k \frac{\partial T}{\partial y}\right|_{y=h-H}=0$, for the boundary region bottom edge,

$T(x, y=h)=20^{\circ} \mathrm{C}$, for the boundary region top edge.

The Finite Element Method is applied to solve the heat conduction equation Eq. (1). The linear triangular elements are used to discretize the computational domain. Since the volumetric heat source depends on the temperature, the system of nonlinear equation, comprising from FEM discretization, needs to be solved. Therefore, the Jacobi iteration method is used. The computational domain mesh was created using a PDE toolbox of MATLAB software. The FEM solver was developed by the authors, and implement to the discretized model. The computations performed in MATLAB allow to determine the temperature distribution within entire underground power cable system.

\section{Soil thermal conductivity effect on temperature distribution in underground power cable system}

The variation in the mother ground thermal conductivity changes the intensity of the heat transfer from power cables. The larger the conductivity, the faster the soil receives the heat, and thus also lowers the temperature of the cable conductor. The soil thermal conductivity changes due to the decrease/increase of the water content (e.g. caused by rains or droughts). The lower the moisture content, the lower the soil thermal conductivity. Therefore, it may happen that the thermal calculations performed for moist soil that meets the security requirements do not satisfy them when the soil is dry.
Figure 4 presents the variation of cable core temperature with the increase in the mother ground thermal conductivity from $0.5 \mathrm{~W} /(\mathrm{m} \mathrm{K})$ to $1 \mathrm{~W} /(\mathrm{m} \mathrm{K})$. It is assumed that the cables are placed in thermal backfill (Fluidized Thermal Backfill) with a thermal conductivity of $1.54 \mathrm{~W} /(\mathrm{m} \mathrm{K})$.

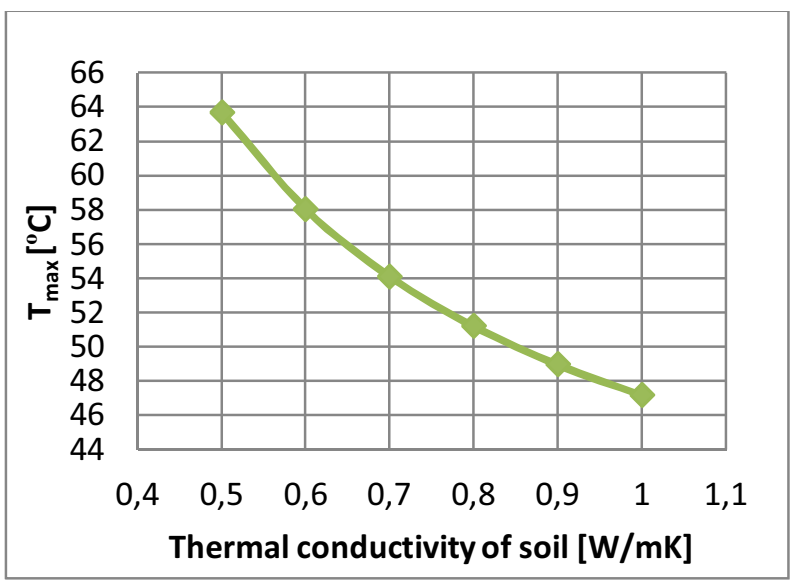

Fig. 4. Variation of cable core temperature with the increase in soil thermal conductivity.

Figure 4 shows the effect of soil thermal conductivity on cable core temperature (central cable conductor). It can be seen that for the analyzed computational case, the two times decrease in the soil thermal conductivity results in the $15^{\circ} \mathrm{C}$ increase of cable core temperature.

The temperature distribution within the cable system (Fig. 5) illustrates well the major impact of soil thermal conductivity on heat transfer.
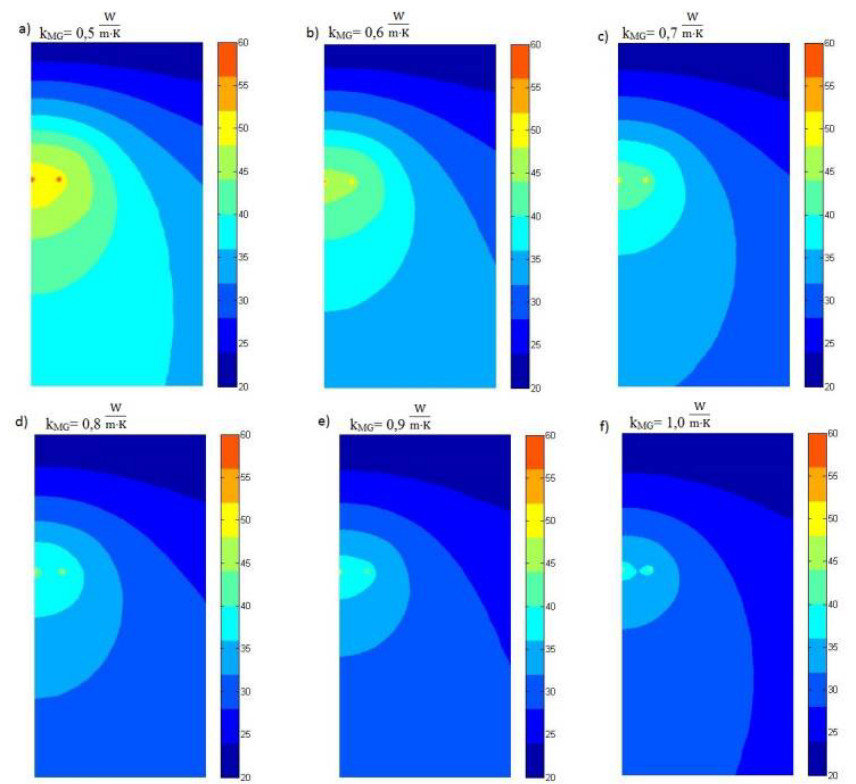

Fig. 5. The temperature distribution around the cable line obtained for cable soil thermal conductivity of a) $0,5 \mathrm{~W} /(\mathrm{m} \cdot \mathrm{K})$, b) $0,6 \mathrm{~W} /(\mathrm{m} \cdot \mathrm{K})$, c) $0,7 \mathrm{~W} /(\mathrm{m} \cdot \mathrm{K})$, d) $0,8 \mathrm{~W} /(\mathrm{m} \cdot \mathrm{K})$, e) 0,9 $\mathrm{W} /(\mathrm{m} \cdot \mathrm{K}), \mathrm{f}) 1,0 \mathrm{~W} /(\mathrm{m} \cdot \mathrm{K})$.

It can be observed that a properly designed cable system for the specified location (with high thermal conductivity), may not perform well in the region where 
the soil thermal conductivity is low. Even small fluctuations in the thermal conductivity value result in different temperature distributions.

\section{Cable backfill thermal conductivity effect on temperature distribution in underground power cable system}

Variation in the thermal conductivity of cable backfill has similar effects (as the soil thermal conductivity changes) on the cable core temperature. Cable backfill has a higher thermal conductivity than the mother ground, and therefore enhances the heat dissipation from buried cables. The study was performed for the soil thermal conductivity of $0.5 \mathrm{~W} /(\mathrm{m} \mathrm{K})$ and cable backfill thermal conductivity varied in a range of $1 \mathrm{~W} /(\mathrm{m} \mathrm{K})$ to $3 \mathrm{~W} /(\mathrm{m}$ $\mathrm{K})$. The first value $(1 \mathrm{~W} /(\mathrm{m} \mathrm{K}))$ refers to the conventional thermal backfill i.e. sand-cement mixture in proportions of $12: 1$. The last value $(3 \mathrm{~W} /(\mathrm{m} \mathrm{K}))$ relates to the POWERCRETE $^{\mathrm{TM}}$ thermal backfill produced by Heidelberg Cement Group.

It should be noted that the higher the backfill thermal conductivity, the increased costs of the cable backfill. Therefore, during the design of underground power cable system, the economic conditions shall be considered.

Figure 6 shows that the increase in the cable backfill thermal conductivity from $1 \mathrm{~W} /(\mathrm{m} \mathrm{K})$ to $3 \mathrm{~W} /(\mathrm{m} \mathrm{K})$ causes the decrease in cable conductor temperature of $7^{\circ} \mathrm{C}$.

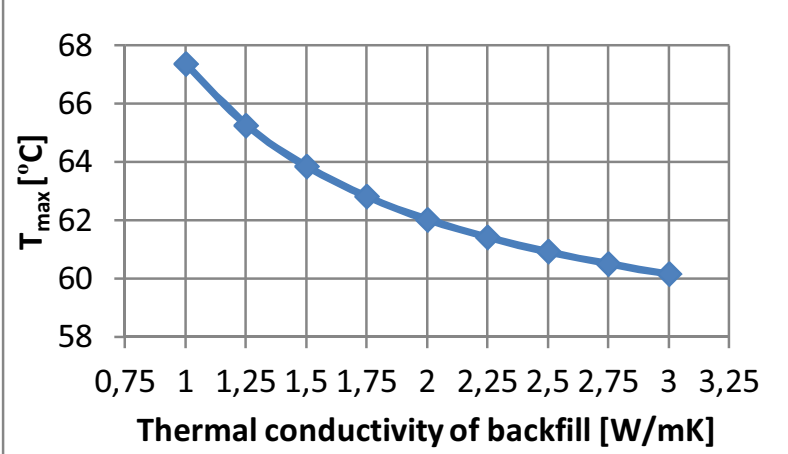

Fig. 6. Variation of cable core temperature with the increase in cable backfill thermal conductivity (the soil thermal conductivity is equal to $0.5 \mathrm{~W} /(\mathrm{m} \mathrm{K})$.

Figure 7 presents the effect of cable backfill thermal conductivity on temperature distribution within the underground power cable system. The value of soil thermal conductivity is assumed as $0.5 \mathrm{~W} /(\mathrm{m} \mathrm{K})$. It can be seen, that for the analyzed system, when the thermal backfill with high thermal conductivity is applied, the temperature gradients within the soil and cable backfill are lower. Hence, the heat is dissipated in a more efficient way from power cables to the surroundings.

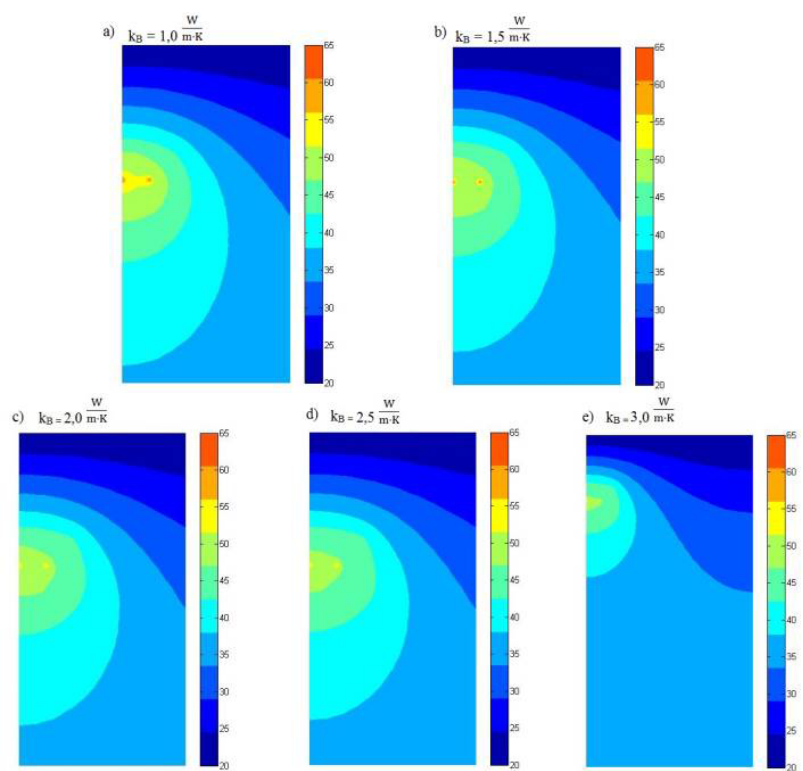

Fig. 7. The temperature distribution around the cable line obtained for cable backfill thermal conductivity of a) 1.0 $\mathrm{W} /(\mathrm{m} \cdot \mathrm{K})$, b) $1.5 \mathrm{~W} /(\mathrm{m} \cdot \mathrm{K})$, c) $2.0 \mathrm{~W} /(\mathrm{m} \cdot \mathrm{K})$, d) $2.5 \mathrm{~W} /(\mathrm{m} \cdot \mathrm{K})$, e) $3.0 \mathrm{~W} /(\mathrm{m} \cdot \mathrm{K})$ and soil thermal conductivity of $1 \mathrm{~W} /(\mathrm{m} \cdot \mathrm{K})$.

Figure 8 compares two computational cases:

- The cables buried in thermal backfill with a thermal conductivity of $3 \mathrm{~W} /(\mathrm{m} \mathrm{K})$ (Fig. 8a)

- the cables buried directly within the soil with a thermal conductivity of $0.5 \mathrm{~W} /(\mathrm{m} \mathrm{K})$ (Fig. 8b) a)

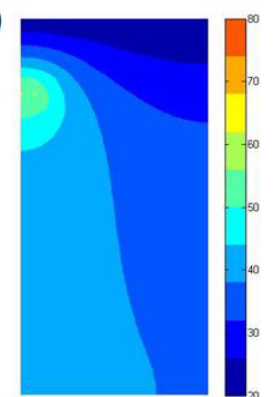

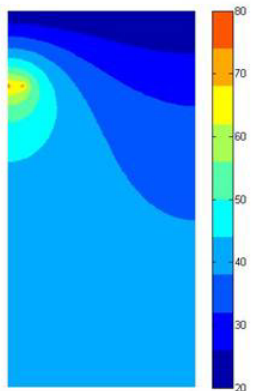

Fig. 8. Temperature distribution in underground power cable system for two cases a) with the use of thermal backfill layer b) without the use of thermal backfill layer.

This example shows that if the cable backfill is not used, but only the mother ground, the cable conductor would reach the temperature of $77,53^{\circ} \mathrm{C}$. It is much higher than the cable design temperature of $65^{\circ} \mathrm{C}$. This example shows how important is to use the thermal backfill layer. When the cable backfill is used instead of mother ground, the cable core temperature is $14^{\circ} \mathrm{C}$ lower.

\section{Conclusions}

This paper presents the thermal analysis of underground power cable system. The case when the cables are arranged in flat formation (in-line) and buried at a depth of $2 \mathrm{~m}$ underground was studied. The Finite Element model that allowed determining the temperature distribution within the system was developed. The 
computations were performed for the thermal conductivity of:

- Thermal Backfill from $1 \mathrm{~W} /(\mathrm{m} \mathrm{K})$ to $3 \mathrm{~W} /(\mathrm{m} \mathrm{K})$

- $\quad$ Mother ground from $0.5 \mathrm{~W} /(\mathrm{m} \mathrm{K})$ to $1 \mathrm{~W} /(\mathrm{m} \mathrm{K})$

Based on the performed analysis it can be concluded that: - soil and thermal backfill conductivity play an important role in cable line design

- the higher the soil thermal conductivity, the lower the cable conductor temperature

- the replacement of mother ground with the thermal backfill material may reduce the cable core temperature up to $14^{\circ} \mathrm{C}$.

\section{References}

1. C.C Hwang, Y.H. Jiang, Extensions to the finite element method for thermal analysis of underground cable systems. Electr Pow Syst Res 64:159-64 (2003)

2. M.S. Al-Saud, M.A. El-Kady, R.D. Findlay, $A$ new approach to underground cable performance assessment. Electr Pow Syst Res 78:907-18 (2008)

3. V.R. De Lieto, L. Fontana, A. Vallati, Thermal analysis of underground electrical power cables buried in non-homogeneous soils. Appl Therm Eng 31:772-8 (2011)

4. V.R. De Lieto, L. Fontana, A. Vallati, Experimental study of the thermal field deriving from an underground electrical power cable buried in nonhomogeneous soils. Appl Therm Eng; 62:390-7 (2014)

5. E. Kroener, A. Vallati, M. Bittelli, Numerical simulation of coupled heat, liquid water and water vapor in soils for heat dissipation of underground electrical power cables. App Therm Eng; 70:510-23 (2014)

6. P. Ocłoń, M. Bittelli, P. Cisek, E. Kroener, M. Pilarczyk, D. Taler, R.V. Rao, A. Vallati, The performance analysis of a new thermal backfill material for underground power cable system Applied Thermal Engineering, 108, pp. 233-250 (2016)

7. P. Ocłoń, P. Cisek, D. Taler, M. Pilarczyk, T. Szwarc, Optimizing of the underground power cable bedding using momentum-type particle swarm optimization method Energy, 92, pp. 230-239 (2015)

8. P. Ocłoń, P. Cisek, M. Pilarczyk, D. Taler, Numerical simulation of heat dissipation processes in underground power cable system situated in thermal backfill and buried in a multilayered soil Energy Conversion and Management, 95, pp. 352-370 (2015)

9. P. Ocłoń, D. Taler, P. Cisek, M. Pilarczyk, FemBased Thermal Analysis of Underground Power Cables Located in Backfills Made of Different Materials Strength of Materials, 47 (5), pp. 770-780 (2015)

10. P. Cisek, P. Ocłoń, M. Pilarczyk. Thermal analysis of operating conditions for The $400 \mathrm{kV}$ underground power cable transmission line as a power plant delivery system. Rynek Energii, 114:70-7 [in polish]. (2014)
11. IEC 60287-2-1: Electric Cables-Calculation of the current rating - Part 2: Thermal resistance - Section 1: calculation of the thermal resistance (1995)

12. IEEE 835-1994: IEEE Standard Power Cable Ampacity Tables (1994) 